\title{
Ilmastonmuutoksen hillintä ruokaturvan edistäjänä - hiilikaupan tarjoamia mahdollisuuksia Saharan eteläpuolisessa Afrikassa
}

\author{
Karoliina Rimhanen ${ }^{1)}$, Helena Kahiluoto ${ }^{1)}$ ja Belay Tseganneh ${ }^{2)}$ \\ ${ }^{1)}$ MTT Mikkeli, Kasvintuotannon tutkimus, Lönnrotinkatu 5, 50100 Mikkeli \\ ${ }^{2)}$ Amhara Regional Agricultural Research Center at Bahir Dar, Ethiopia. \\ karoliina.rimhanen@mtt.fi, helena.kahiluoto@mtt.fi,kassie.tseganeh@mtt.fi
}

\section{Tiivistelmä}

Ilmastonmuutoksen ovat aiheuttaneet ensisijaisesti teollisuusmaat, mutta sen vaikutukset uhkaavat erityisesti maapallon köyhimpiä kehitysmaita. Afrikassa ilmaston lämpenemisen on ennustettu vähentävän satotasoja 10-20\% tulevina vuosikymmeninä. Kansainvälinen emissiokauppa tarjoaa mahdollisuuden parantaa ilmastotasa-arvoa kehitysmaiden ja kehittyneiden maiden välillä. Kasvihuonekaasupäästöjä vähentämällä ja hiilinieluja lisäämällä kehitysmaat voivat saada tuloja ja samalla kehittää maataloutensa tuottavuutta.

Tämän tutkimuksen tavoitteena oli luoda analyyttinen viitekehys niiden tekijöiden tutkimiseksi, jotka vaikuttavat maatalouden hillintäkeinojen mahdollisuuksiin edistää ruokaturvaa muuttuvassa ilmastossa, ja soveltaa tätä viitekehystä Saharan eteläpuoliseen Afrikkaan, Etiopiaan ja Central Rift Valley:iin (CRV). Tässä esitellään alustavia tuloksia, jotka palvelevat väitöskirjatyön fokusointia ja yksityiskohtaista suunnittelua.

Analyyttinen viitekehys agroekologisten ja sosioekonomisten tekijöiden tarkastelua varten luotiin kirjallisuuden ja haastatteluiden avulla. Aiempaan tutkimukseen tukeutuen arvioitiin eri maankäyttömuotojen ilmastonmuutoksen hillintäpotentiaali Saharan Eteläpuolisessa Afrikassa, Etiopiassa ja CRV:ssä. Haastattelututkimuksen avulla määritettiin Etiopian ja CRV:n maatalouteen soveltuvia hillintätoimia, jotka samalla edistäisivät ilmastonmuutokseen sopeutumista ja ruokaturvaa. Kyselyllä kartoitettiin myös mahdollisia esteitä toimenpiteiden toteuttamiselle sekä kansainväliseen hiilikauppaan osallistumiselle.

Ruokaturvan parantamisen näkökulmasta lupaavimpia ilmastonmuutoksen hillintäkeinoja näyttävät olevan ne, jotka paitsi luovat tuloja hiilimarkkinoilta myös lisäävät maan tuottavuutta ja ehkäisevät maan viljavuuden heikkenemistä. Saharan eteläpuolisessa Afrikassa ja etenkin Etiopiassa suurin potentiaali lisätä maan orgaanisen hiilen varastoja on jo tuotantokyvyltään ratkaisevasti heikentyneillä viljelemättömillä mailla. CRV:ssä myös viljeltyjen peltojen merkitys on suuri. Ilmastonmuutoksen lisätessä kuivuutta alueella kasvukunnoltaan heikentyneiden maiden kunnostamisen merkitys kasvaa.

Sopivia viljelykiertoja, peltometsäviljelyä sekä lannan kierrättämistä peltoon sen polttamisen sijaan pidettiin parhaina keinoina kohottaa peltojen viljavuutta ja sitoa hiiltä. Esteitä joillekin keinoille asettivat alueen agroekologia ja ilmasto-olot, kuten sademäärien suuri vaihtelu, tietämättömyys, vaihtoehtoisten energialähteiden puute, teknologioiden kehittymättömyys ja köyhyys. Suurimpana esteenä kansainväliseen hiilikauppaan osallistumiselle pidettiin tietämättömyyttä hiilikaupasta ja sen edellytyksistä.

Asiasanat: hiilinielu, maatalousmaa, ruokaturva, ilmastonmuutos, hiilikauppa, Etiopia, analyyttinen viitekehys, kirjallisuustutkimus, haastattelututkimus 


\section{Johdanto}

Ruokaturvan toteutuminen on yksi suurimmista ihmiskuntaa koskettavista haasteista. Väistämätön ilmastonmuutos, väestönkasvu ja urbaanin väestön elintason nousu uhkaavat tulevaisuudessa erityisesti kehitysmaissa elävien köyhien ruokaturvan toteutumista (IPCC 2007). Saharan eteläpuolisessa Afrikassa (SSA) globaalin muutoksen on ennustettu heikentävän merkittävästi maatalouden tuotantokykyä ja laskevan tuloja vaikeuttaen ruokaturvan toteutumista. Afrikassa ravintokasvien satotasojen on ennustettu laskevan 10-20 \% lähivuosikymmeninä (Thornton ym. 2009).

Kehittyneet maat kantavat suurimman vastuun ilmastonmuutoksen aiheuttamisesta (IPCC 2007). Vuonna 2005 annex I maiden (teollisuusmaat ja siirtymätalousmaat) osuus koko maailman kasvihuonekaasupäästöistä oli noin $50 \%$, vähiten kehittyneiden maiden osuuden ollessa alle $2 \%$. Henkilöä kohti lasketut päästöt olivat annex I maissa $13,8 \mathrm{tCO}_{2}$ ja vähiten kehittyneissä maissa 0,8 $\mathrm{tCO}_{2}$ (WRI 2009). Kehittyneissä maissa suurin osa päästöistä on peräisin energiantuotannosta kun taas kehitysmaissa maa- ja metsätalouden osuus päästöistä on suuri. Etiopiassa maatalouden kasvihuonekaasupäästöt edustavat $67 \%$ maan kokonaispäästöistä (WRI 2009). Tulevaisuudessa väestön- ja varallisuuden kasvun on arvioitu kasvattavan maataloudesta peräisin olevia päästöjä entisestään, erityisesti kehitysmaissa (Smith ym. 2008).

Kansainvälinen emissiokauppa tarjoaa mahdollisuuden kohtuullistaa kehitysmaiden ja kehittyneiden maiden eriarvoista asemaa. Kioton pöytäkirja velvoittaa sopimuksen ratifioineet teollisuusmaat vähentämään kasvihuonekaasupäästöjään keskimäärin 5 \% vuoden 1990 tasosta vuosien 2008-2012 aikana (UNFCCC 2009). Maat, joita päästövelvoite koskettaa voivat toteuttaa päästövähennyksen joko kotimaassaan tai Kioton joustomekanismeja hyödyntämällä toisessa maassa. Päästökauppa on markkinamekanismi, jossa toinen osapuoli maksaa toiselle osapuolelle päästövähennyksen tai nieluhankkeen toteuttamisesta. Puhtaan kehityksen mekanismi (The Clean Development Mechanism eli CDM) mahdollistaa hankkeen toteuttamisen kehitysmaassa. Hankkeista ansaitut sertifioidut päästövähennysyksiköt (Certified Emission Reduction Units eli CERs) voi rahoittajaosapuoli vähentää omasta päästövähennysvelvoitteestaan. Nieluhankkeiden tapauksessa hankkeista ansaitaan poistoyksiköitä (Removal Units, RMUs). Puhtaan kehityksen mekanismien tarkoituksena on edistää kestävää kehitystä ja motivoida kehitysmaat osallistumaan ilmastonmuutoksen hillitsemistalkoisiin (UNFCCC 2009). Kioton sopimus mahdollistaa päästövähennys-/nieluhankkeiden rahoittamisen ja ilmastonmuutokseen sopeutumisen, joka on erityisen tärkeätä monille kehitysmaille. Ilmastonmuutoksen hillintäkeinojen omaksuminen ja päästövähennyksien myyminen luo uusia tulolähteitä paikalliselle väestölle edistäen ruokaturvan toteutumista. Tällä hetkellä maatalouden toimenpiteet, jotka edistävät hiilen sitoutumista maahan, ja metsänhakkuuta estävät hankkeet, eivät sisälly CDM:n ohjelmaan. Nämä toimenpiteet edistäisivät merkittävällä tavalla kestävää kehitystä ja ruokaturvaa kehitysmaissa (Bryan et al. 2008). Kioton joustomekanismien uudistaminen onkin Kööpenhaminan ilmastokokouksen asialistalla joulukuussa 2009. Lisäksi vapaaehtoiset hiilimarkkinat tarjoavat välittömiä mahdollisuuksia kehitysmaille hyötyä ekosysteemipalveluiden kaupasta.

Ilmastonmuutoksen hillintäkeinot sisältävät toimia, joilla vähennetään kasvihuonekaasupäästöjä, lisätään kasvihuonekaasunieluja ja vältetään päästöjä (Smith ym. 2008). Maataloussektorilla monet menetelmät, jotka hillitsevät ilmastonmuutosta parantavat samalla sopeutumista ilmastonmuutoksen vaikutuksiin. Esimerkiksi monet menetelmät, jotka lisäävät hiilen sitoutumista maahan parantavat myös maan tuottavuutta, ja täten ruoan saatavuutta (Lal 2004).

Afrikan maatalouden osuus koko maailman maataloussektorin teknisestä ilmastonmuutoksen hillitsemispotentiaalista arvioidaan olevan $17 \%$, ja sen ennustetaan tulevaisuudessa edelleen kasvavan etenkin Saharan eteläpuolisessa Afrikassa. Lisäksi Afrikan koko metsäsektorin ilmastonmuutoksen hillitsemispotentiaalin on arvioitu olevan $14 \%$ ja vältetyn metsänhakkuun $29 \%$ koko maailman metsäsektorin potentiaalista vähentää kasvihuonekaasupäästöjä (Smith ym. 2008). Toistaiseksi Saharan eteläpuolisen Afrikan osuus kansainvälisestä hiilikaupasta on ollut marginaalinen. Afrikalla on kuitenkin hyvät mahdollisuudet lisätä päästövähennyshankkeiden määrää. Päästöjen hillintätoimien toteuttaminen edellyttää kuitenkin kansainvälisten ja paikallisten instituutioiden tukea ja järjestelmien kehittämistä sekä tutkimustietoa paikallisiin agroekologisiin olosuhteisiin soveltuvista menetelmistä.

Tämän tutkimuksen tavoitteena oli luoda analyyttinen viitekehys agroekologisten ja sosioekonomisten tekijöiden tutkimiseksi, jotka vaikuttavat maatalouden hillintäkeinojen mahdollisuuksiin edistää ruokaturvaa muuttuvassa ilmastossa, ja soveltaa tätä viitekehystä Saharan eteläpuoliseen Afrikkaan, Etiopiaan ja Central Rift Valley:iin (CRV). 


\section{Aineisto ja menetelmät}

Analyyttinen viitekehys pyrkii kuvaamaan sosioekonomisten ja agroekologisten tekijöiden vaikutuksia mahdollisuuksiin toteuttaa hillintätoimia kehitysmaiden maatalous- ja maankäyttösektoreilla ja edistää paikallista ruokaturvaa. Se perustuu hiilikauppaa ja ruokaturvaa käsitteleviin tutkimusartikkeleihin ja raportteihin sekä omaan haastattelututkimukseemme. Suoritimme pilottihaastattelututkimuksen Etiopian Central Rift Valley:ssa määritelläksemme i) maataloussektorin hillintätoimia, jotka samalla edistäisivät ilmastonmuutokseen sopeutumista ja ruokaturvaa ii) mahdollisia esteitä hillintätoimenpiteiden toteuttamiselle ja iii) pullonkauloja osallistua kansainväliseen hiilikauppaan. Haastatteluun valittiin satunnaisotannalla 16 viljelijää (joista 14 kasvi-kotieläintuottajia ja kaksi kasvintuottajaa), yksi maatalousalan tutkija, kaksi maatalousalan neuvontasektorin edustajaa, kaksi maataloushallinnon edustajaa, kaksi metsäalan asiantuntijaa ja yksi ympäristöalan kansalaisjärjestön edustaja Central Rift Valley:n alueelta Keski-Etiopiasta. Haastattelun toteutti etiopialainen maatalousalan tutkija puolistrukturoituun kysymyslomakkeeseen perustuvalla osallistuvan haastattelututkimuksen menetelmällä. Vastaukset analysoitiin alustavasti aineiston sisällön jäsentämiseksi.

Ilmastonmuutoksen kokonaishillintäpotentiaali arvioitiin Saharan Eteläpuolisen Afrikan, Etiopian ja Central Rift Valley:n tämänhetkisten maatalouden maankäyttömuotojen perusteella. Maatalousmaa jaettiin viljelymaaksi, laidunmaaksi ja viljavuudelta heikentyneeksi maaksi ja eri maankäyttömuotojen pinta-ala (Faostat, Fao Terrastat ja Jansen ym. 2007) kerrottiin hiilen sitoutumiskyvyn potentiaalilla eri maankäyttöluokissa tropiikissa (Batjes 2004, Bruce 1999, Lal ym. 1998 sekä Sampson \& Scholes 2000).

\section{Tulokset ja tulosten tarkastelu}

Analyyttisessä viitekehyksessä (Kuva 1) tuodaan esiin vaikutusreitit, joiden kautta hiilikaupan ilmastonmuutosta hillitsevät toimet vaikuttavat ruokaturvaan kehitysmaissa. Nielu- tai päästövähennyshankkeilla ansaitut tulot parantavat kehitysmaissa resurssien saatavuutta ja edistävät ruoanhankintamahdollisuuksia. Nieluhankkeilla on lisäksi maan viljavuuden lisääntymisen kautta maatalouden ruoantuotantoa edistävä vaikutus. Hiilikauppaan osallistuminen, hillintätoimien valitseminen ja hyödyn oikeudenmukainen jakautuminen edellyttävät instituutioiden tukea ja kehittämistä sekä monipuolisia resursseja. Kansainvälisellä ilmastopolitiikalla on suuri vaikutusmahdollisuus edistää ilmastotasa-arvon toteutumista teollisuusmaiden ja kehitysmaiden välillä sisällyttämällä maa- ja metsätalouden hillintäkeinot osaksi Kioton joustomenetelmiä ja kehittämällä järjestelmää kehitysmaiden maataloussektoria suosivaksi. Tällä hetkellä päästövähennys-/nieluhankkeen hyväksyminen osaksi hiilikauppajärjestelmää edellyttää hankkeen lähtötilanteen tarkkaa selvitystä, päästövähennyksen todentamista ja todistusta, ettei päästövähennystä olisi tapahtunut ilman hanketta. Koko varmentamisprosessin hallitseminen edellyttää paljon tietoa, teknologiaa ja resursseja. Ilmastotasa-arvon kohtuullistaminen vaatii järjestelmien kehittämistä niin, että köyhimpien viljelijöiden osallistuminen hiilikauppaan helpottuu ja poistoyksiköiden kaupasta syntyneet hyödyt jakautuvat oikeudenmukaista yhteisön hyväksi. 


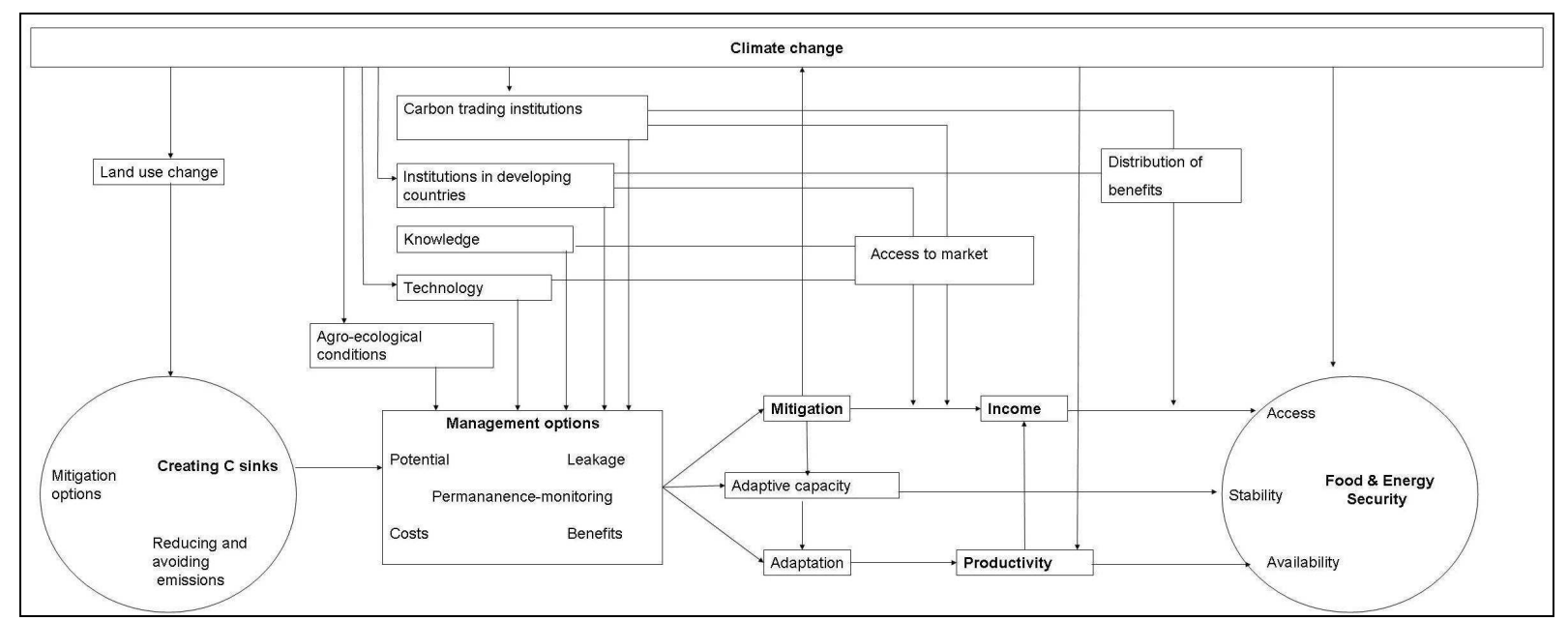

Kuva 1. Analyyttinen viitekehys kuvaa, miten ilmastonmuutosta hillitsemällä voidaan parantaa ruokaturvaa kehitysmaissa.

Haastattelututkimuksen mukaan vaihteleva sadanta, resurssien liiallinen käyttö ja alhainen tulotaso uhkaavat ruokaturvan toteutumista Etiopian Central Rift Valley:ssa. Kestämättömät maankäytön menetelmät riittävien resurssien puuttuessa ovat johtaneet maataloustuotannon alentumiseen ja maan pilaantumiseen. Lupaavina ilmastonmuutoksen hillitsemiskeinoina haastateltavat pitivät maatalouden menetelmiä, jotka lisäävät maan tuottavuutta, ehkäisevät maan pilaantumista ja luovat tuloja köyhille pienviljelijöille. Hiilen sitominen maaperään ja sitä kautta maan viljavuuden parantaminen oli vastaajien mielestä merkittävä tekijä lisätä ruoan tuotantoa. Menetelmätasolla monipuolisia viljelykiertoja, peltometsäviljelyä sekä lannan kierrättämistä lannoituskäyttöön polttamisen sijaan pidettiin alueelle sopivina keinoina parantaa peltojen viljavuutta. Esteenä ilmastonmuutoksen hillintätoimien toteuttamiselle pidettiin joidenkin menetelmien sopimattomuutta paikallisiin olosuhteisiin, tietämättömyyttä, vaihtoehtoisten energiamuotojen puutetta, teknologioiden puuttumista ja köyhyyttä. Suurimpana esteenä kansainväliseen hiilikauppaan osallistumiselle pidettiin tietämättömyyttä hiilikaupasta ja sen edellytyksistä.

Ilmastonmuutoksen hillintäpotentiaali kuvaa maatalouden toimenpiteiden myötä maaperään sitoutuvan hiilen määrää maankäyttöluokittain Saharan Eteläpuolisessa Afrikassa (SSA), Etiopiassa ja Central Rift Valley:ssa (CRV) (Kuva 2). SSA:n ja Etiopian tasoilla suurin potentiaali lisätä maan orgaanisen hiilen varastoja on mailla, joiden tuotantokyky on vakavasti heikentynyt lähinnä kestämättömien maankäyttötapojen vuoksi. Sekä Etiopian että SSA:n tasoilla noin $30 \%$ kokonaismaa-alasta on vakavasti tai erittäin vakavasti heikentynyt viljavuus (FAO 2003). SSA:n tasolla myös laidunmailla, joita erityisesti suuri eläinmäärä kuormittaa on suuri potentiaali lisätä hiilen sitoutumista maaperään.

Eri maankäyttöluokkien yhteenlaskettu ilmastonmuutoksen hillintäpotentiaali vastaa 40-100\% SSA:n ja 120-260 \% Etiopian maatalouden kokonaispäästöistä, mikäli oletetaan, että hillitsemistoimet toteutetaan kaikilla olemassa olevilla maa-aloilla. Jos hillitsemistoimet toteutettaisiin $20 \%$ peltomailla, $10 \%$ laidunmailla ja $5 \%$ pilaantuneilla mailla (Sampson \& Scholes 2000) vastaisi maatalouden kokonaisilmastonmuutoksenhillintäpotentiaali 3-9 \% Etiopian ja 10-20 \% SSA:n vuosittaisista maatalouden päästöistä. CRV:n tasolla erotimme viljelymaan ja peltometsäviljelymaan tarkemman maankäyttöluokituksen avulla (Jansen et al. 2007). Viljelymaalla ja peltometsäviljelymaalla oli suurin ilmastonmuutoksen hillitsemispotentiaali CRV:ssa. 


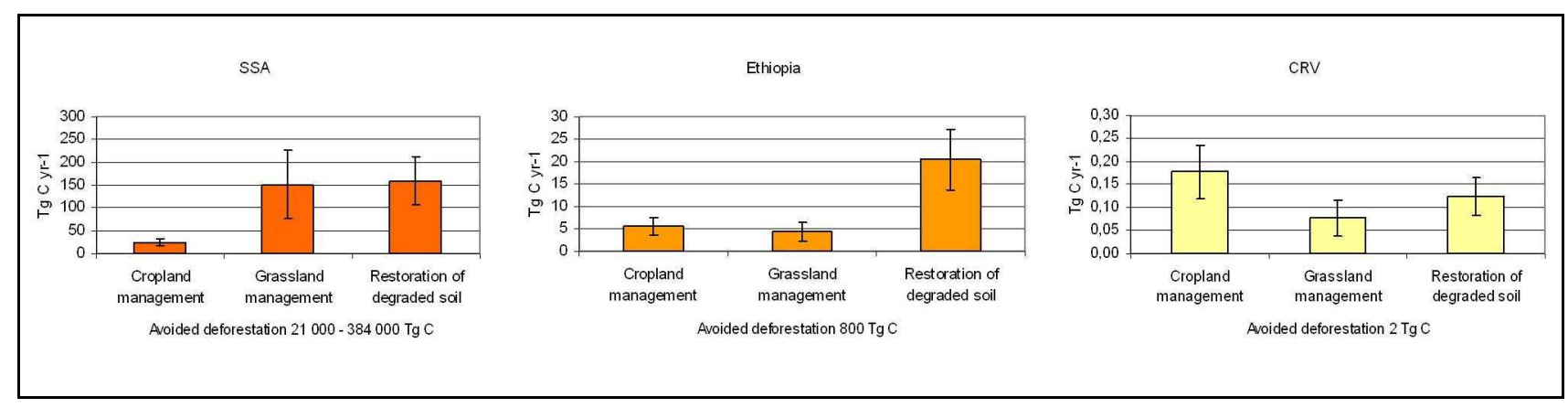

Kuva 2. Laskennallinen hiilen tekninen sitoutumispotentiaali, jos menetelmät toteutettaisiin kaikilla kyseisen maankäyttötyypin mailla.

\section{Johtopäätökset}

Saharan eteläpuolisen Afrikan maatalouden hiilinielupotentiaalin hyödyntäminen hiilikaupan avulla voisi hillitä ilmastonmuutosta, parantaa maatalouden ruoantuotantokykyä ja resurssien saatavuutta kehitysmaissa. Ilmastotasa-arvon kohtuullistaminen edellyttää kansallisten ja kansainvälisten järjestelmien tukea ja kehittämistä niin, että köyhimpien maiden viljelijöiden osallistuminen hiilikauppaan helpottuisi ja poistoyksiköiden kaupasta syntyneet hyödyt jakautuisivat oikeudenmukaisesti.

Merkittävä ilmastonmuutoksen hillintäpotentiaali on erityisesti viljavuudeltaan heikentyneillä mailla, joissa orgaanisen hiilen määrää on kunnostustoimilla mahdollisuus lisätä merkittävästi. Tulevaisuudessa ilmastonmuutoksen lisätessä kuivuutta Etiopiassa, kasvukunnoltaan heikentyvien maiden kunnostamisen merkitys voikin kasvaa entisestään. Esteenä ilmastonmuutoksen hillintätoimien toteuttamiselle pidettiin joidenkin menetelmien sopimattomuutta paikallisiin olosuhteisiin, tietämättömyyttä, teknologian kehittymättömyyttä, vaihtoehtoisten energiamuotojen puutetta ja köyhyyttä. Suurimpana esteenä kansainväliseen hiilikauppaan osallistumiselle pidettiin tietämättömyyttä hiilikaupasta ja sen edellytyksistä. Myös tarvittavien paikallisten instituutioiden, kuten verifiointijärjestelmän rakentaminen sekä empiirisen tiedon synteesi ja tietoaukkojen kattaminen maatalousmaan orgaanisen aineksen kartuttamisen keinoista asettavat haasteita.. 


\section{Kirjallisuus}

Batjes, N.H. 2004. Estimation of soil carbon gains upon improved management within croplands and grasslands of Africa. Environment, Development and Sustainability 6: 133-143.

Bruce, J.P., Frome, M., Haites, E., Janzen, H., Lal, R. and Paustian, K.: 1999, Carbon sequestration in soils, Journal of Soil and Water Conservation 54, 382-389.

Bryan, E., Akpalu, W., Yesuf, M. \& Ringler, C. 2008, Global Carbon Markets Are There Opportunities for Sub-Saharan Africa? Internal Food Policy Research Institute, Environment and Production Technology Division.

FAO 2003. Terrastat. Land degradation severity and population distribution. Available: http://www.fao.org/AG/agl/agll/terrastat/.

IPCC 2007, (Intergovernmental Panel on Climate Change), Climate Change 2007. The Physical Science Basis. Contribution of Working Group I to the Fourth Assessment Report of the Intergovernmental Panel on Climate Change. Summary for Policy Makers. Cambridge University Press, Cambridge, UK.

Jansen, H., Hengsdijk, H., Legesse, D., Ayenew, T., Hellegers, P. \& Spliethoff, P. 2007, Land and water resources assessment in the Ethiopian Central Rift Valley : project: ecosystems for water, food and economic development in the Ethiopian Central Rift Valley, Alterra, Wageningen.

Lal, R., Kimble, J.M., Follet, R.F. and Cole, C.V. (eds.): 1998, The Potential of U.S. Cropland to Sequester Carbon and Mitigate the Greenhouse Effect, Chelsea, MI, Ann Arbor Press, pp. 128.

Lal, R. 2004. "Soil carbon sequestration to mitigate climate change", Geoderma, vol. 123, no. 1-2, pp. 1-22.

Sampson, R. N., Scholes, R. J., Cerri, C., Erda, L., Hall, D. O., Handa, M., Hill, P., Howden, M., Janzen, H., Kimble, J., Lal, R., Marland, G., Minami, K., Paustian, K., Read, P., Sanchez, P. A., Scoppa. C., Solberg, B., Trossero, M. A., Trumbore, S., Van Cleemput, O., Whitmore, A., and Xu, D. 2000,

"'Additional Human-Induced Activities - Article 3.4', in Watson, R. T., Noble,

I. R., Bolin, B., Ravindranath, N. H., Verardo, D. J., and Dokken, D. J. (eds.), Land Use, Land-

Use Change, and Forestry: A Special Report of the Intergovernmental Panel on Climate Change" in , pp.

Cambridge University Press, Cambridge, pp. 183-281.

Smith, P., Martino, D., Cai, Z., Gwary, D., Janzen, H., Kumar, P., McCarl, B., Ogle, S., O'Mara, F., Rice, C., Scholes, B., Sirotenko, O., Howden, M., McAllister, T., Pan, G., Romanenkov, V., Schneider, U., Towprayoon, S., Wattenbach, M. \& Smith, J. 2008, "Greenhouse gas mitigation in agriculture", Philosophical Transactions of the Royal Society B-Biological Sciences, vol. 363, no. 1492, pp. 789-813.

Thornton, P.K., Jones, P.G., Alagarswamy, G. \& Andresen, J. 2009, "Spatial variation of crop yield response to climate change in East Africa", Global Environmental Change, vol. 19, no. 1, pp. 54-65.

UNFCCC 2009. Kyoto Protocol [Homepage of United Nations Framework Convention on Climate Change], [Online]. Available: http://unfccc.int/kyoto_protocol/items/2830.php.

WRI 2009. Climate Analysis Indicators Tool (CAIT) Version 6.0. Washington, DC. World Resources Institute. 